\title{
Management and outcomes of side effects with focus on anaemia in patients with hepatitis $C$ genotype 1 infection: the telaprevir early access program in patients from Romania
}

\author{
Adrian Streinu-Cercel ${ }^{1,2^{*}}$, Anca Victorița Trifan ${ }^{3,4}$, Florin Alexandru Căruntu ${ }^{1,2}$, Ioan Sporea ${ }^{5}$, \\ Liliana Simona Gheorghe ${ }^{1,6}$, Manuela Curescu, ${ }^{5}$, Mihai Mircea Diculescu ${ }^{1,6}$, Mihai Voiculescu, ${ }^{1,6}$, Oliviu Pascu , \\ Isabelle Lonjon-Domanec ${ }^{8}$, Andrew Martin Hill ${ }^{9}$, Sorin Rugină ${ }^{10,11}$
}

From The 9th Edition of the Scientific Days of the National Institute for Infectious Diseases Prof Dr Matei Bals Bucharest, Romania. 23-25 October 2013

\section{Background}

Anaemia is a common adverse event during treatment for HCV infection. HEP3002 is an ongoing, open-label, early access program of telaprevir in 16 countries, for patients with genotype 1 hepatitis $C$ with severe fibrosis or compensated cirrhosis. This analysis is of the data from the 209 Romanian patients, evaluated after 16 weeks of treatment.

\section{Method}

Liver biopsy or non-invasive tests showing severe fibrosis or cirrhosis were required at entry. 209 patients from Romania were treated with telaprevir in combination with peginterferon alfa and ribavirin (PR) for 12 weeks, followed by PR for 12 or 36 weeks. Use of iron supplements, erythropoietin (EPO) and blood transfusions was permitted. Anaemia included the clinically significant adverse event terms of anaemia or haemoglobin $(\mathrm{Hb})$ reduction. All analyses were on the Intent to Treat (ITT) population, using 16 week data.

\section{Results}

Mean age was 52 years; $47 \%$ were male and $100 \%$ Caucasian, 59\% had HCV RNA levels $\geq 800,000 \mathrm{IU} / \mathrm{mL}, 58 \% / 42 \%$ had severe fibrosis/cirrhosis, and $2 \%$ had genotype 1a. Up to week $16,57 \%$ of patients developed grade $1-4$ anaemia, with $41 \%$ Grade $3-4$ cases (3\% grade 4$)$; 72 patients $(34 \%)$

\footnotetext{
* Correspondence: astreinucercel@yahoo.com

${ }^{1}$ Carol Davila University of Medicine and Pharmacy, Bucharest, Romania

Full list of author information is available at the end of the article
}

\section{Table 1}

\begin{tabular}{lll}
\hline Type of anaemia & Definition & $\begin{array}{l}\text { Total } \\
(\mathrm{n}=209)\end{array}$ \\
\hline Grade $1-2$ & $\begin{array}{l}\text { Hb } 9-10.9 \text { or } 2.5-4.4 \mathrm{~g} / \mathrm{dL} \\
\text { decrease }\end{array}$ & $33(16 \%)$ \\
Grade $3-4$ & $\begin{array}{l}\mathrm{Hb}<8.9 \text { or }>4.5 \mathrm{~g} / \mathrm{dL} \\
\text { decrease }\end{array}$ & $86(41 \%)$ \\
D/C for anaemia & & $1(<1 \%)$ \\
Anaemia as Serious AE & & $9(4 \%)$ \\
\hline
\end{tabular}

dose-reduced ribavirin, and $1(<1 \%)$ discontinued treatment for anaemia. Results are shown in Table 1.

Up to week $16,46 \%$ of patients developed grade 3 or 4 adverse events including 5 patients (2\%) who developed grade 3 or 4 rash; $9 \%$ of patients had serious adverse events. Nine patients (4\%) discontinued TVR due to adverse events, including 6 patients (3\%) who discontinued due to rash. No deaths occurred during the study.

\section{Conclusion}

In this telaprevir early access program for patients with severe fibrosis or compensated cirrhosis, Grade 3 or 4 anaemia was reported in $41 \%$ of patients, but discontinuation for anaemia was rare $(<1 \%)$. Anaemia was principally managed by ribavirin dose reduction.

\footnotetext{
Authors' details

${ }^{1}$ Carol Davila University of Medicine and Pharmacy, Bucharest, Romania. ${ }^{2}$ National Institute for Infectious Diseases "Prof.Dr. Matei Balş", Bucharest, Romania. ${ }^{3 " G r . T . P o p a " ~ U n i v e r s i t y ~ o f ~ M e d i c i n e ~ a n d ~ P h a r m a c y, ~ l a s ̧ i, ~ R o m a n i a . ~}$ ${ }^{4}$ Institute of Gastroenterology and Hepatology, "St Spiridon" Emergency Hospital,
} 
laşi, Romania. ${ }^{5}$ Victor Babeş University of Medicine and Pharmacy, Timişoara, Romania. ${ }^{6} \mathrm{C}$ enter for Digestive Diseases and Liver Transplantation, Fundeni

Clinical Institute, Bucharest, Romania. ${ }^{7}$ Regional Institute of Gastroenterology and

Hepatology, Cluj-Napoca, Romania. ${ }^{8}$ Janssen Pharmaceuticals, Paris, France.

${ }^{9}$ MetaVirology Ltd, London, UK. ${ }^{10}$ Ovidius University, Constanța, Romania.

${ }^{11}$ Clinical Hospital of Infectious Diseases, Constanța, Romania.

Published: 16 December 2013

doi:10.1186/1471-2334-13-S1-P59

Cite this article as: Streinu-Cercel et al:: Management and outcomes of

side effects with focus on anaemia in patients with hepatitis $C$

genotype 1 infection: the telaprevir early access program in patients

from Romania. BMC Infectious Diseases 2013 13(Suppl 1):P59.

Submit your next manuscript to BioMed Central and take full advantage of:

- Convenient online submission

- Thorough peer review

- No space constraints or color figure charges

- Immediate publication on acceptance

- Inclusion in PubMed, CAS, Scopus and Google Scholar

- Research which is freely available for redistribution

Submit your manuscript at www.biomedcentral.com/submit 